Tanja KUŠTOVIĆ

UDK 272-282.7:003.349.1

Filozofski fakultet

27-246:811.163.42

Zagreb

tanja.kustovic@ffzg.hr

Izvorni znanstveni članak

Primljen: 25. travnja 2019.

Prihvaćen: 9. listopada 2019.

\title{
PRIJEVOD URAŠKOG GLAGOLJSKOG NOVOG TESTAMENTA I MOGUĆI UTJECAJI JEZIKA ISTARSKIH HRVATSKOCRKVENOSLAVENSKIH KODEKSA (NA PRIMJERU DRUGOG BERAMSKOG BREVIJARA)
}

U Urachu kraj Tübingena je otisnuto protestantsko izdanje Novoga testamenta, na glagoljici (I. dio 1562. i II. dio 1563.). Poznato je da su u njegovu prevođenju sudjelovali Istranin Stipan Konzul i drugi istarski svećenici. Svi su oni dobro poznavali crkvenoslavenske kodekse nastale i upotrebljavane u središnjoj Istri, baš kao što su i Beramski brevijari. Iako je dobro poznato i već potvrđeno, da su protestanti napravili odlučan iskorak prema narodnom jeziku zanimat će nas - na temelju konkretne usporedne analize - u kolikoj je mjeri to doista i provedeno, odnosno koliko se u njima ipak odražava poznavanje crkvenoslavenskih prijevoda. Osim toga, ustanovljena je bliskost protestantskih prijevoda s latiničkim lekcionarima, pri čemu se utvrdila sličnost sa Zborovčićevim lekcionarom iz 1543. godine, otisnutim u Veneciji, a riječ je o drugom izdanju Lekcionara Bernardina Splićanina (1495.). Analiza je napravljena na tekstu Prve Epistole svetoga Pavla Korinćanima (1 Kor 11,20-33) koji se nalaze u Drugom beramskom brevijaru iz 15. stoljeća kao predstavniku srednjoistarskog kodeksa, te u Lekcionaru Bernardina Splićanina i u II. dijelu glagoljicom pisanog protestantskog izdanja Novoga testamenta. Usporedbom se dolazi do zaključka da čakavski, tj. hrvatski elementi prevladavaju u Novom testamentu, dok je udio crkvenoslavenskih elemenata u ovom dijelu teksta zanemariv.

Ključne riječi: Novi testament, lekcionar, brevijar, crkvenoslavenski jezik, hrvatski jezik

\section{UVOD}

Reformacija započinje objavom teza o crkvenim oprostima Martina Luthera u Wittenbergu 1517. godine. Riječ je o pokretu koji se prvenstveno širio 
tiskanom knjigom. Jedan od ciljeva pokreta bio je prevesti Bibliju na narodne jezike kako bi ona svima bila razumljiva. Pokret se proširio na okolne zemlje pa dolazi i u Sloveniju, a ubrzo i u Hrvatsku. Što se tiče Slovenije, tu je veliku ulogu imao Primož Trubar kojemu se pridružuje Petar Pavao Vergerije mlađi. Upravo je Primož Trubar snažno utjecao na početke hrvatskog reformacijskog pokreta (HRVATSKI PROTESTANTSKI PISCI 2000: 11) i surađivao sa Stipanom Konzulom - glagoljašem iz Buzeta koji je pristao uz protestantski pokret. Sve ih je primio u Urachu u blizini Tübingena würtemberški vojvoda Krištof. Tamo je barun Ivan Ungnad, također pristaša protestantizma, ustanovio južnoslavenski Biblijski zavod u kojem su tiskana protestantska izdanja, što uključuje prijevod Svetoga pisma i poučnu vjersku književnost. Njihovi su tekstovi objavljeni trima pismima: glagoljicom, ćirilicom i latinicom, s namjerom da tako budu dostupni na što većem prostoru.

Novi testament objavili su hrvatski protestanti 1562. i 1563. godine dvama pismima: glagoljicom (1562./1563.) i ćirilicom (1563.). U literaturi je postavljena pretpostavka da je Novi testament kao svoj predložak mogao imati i neki kodeks nastao u središnjoj Istri. Naime, poznato je da su u prevođenju glagoljskog Novog testamenta sudjelovali, uz Istranina Stipana Konzula, rodom iz Buzeta, a župnika iz Starog Pazina, i drugi istarski svećenici kao što su Juraj Cvečić i Ivan Fabijanić iz Pazina (BUČAR 1910: 108), te Istrani Matija Pomazanić i Juraj Juričić (BUČAR 1910: 109, 110). Konzul i Cvečić preveli su Poslanice sv. Pavla Rimljanima, Korinćanima i Galaćanima (BUČAR 1910: 113). Cvečić je sam preveo poslanice sv. Pavla Efežanima, Filipljanima, Kološanima, Solunjanima, Timoteju, Titu i Filemonu (BUČAR 1910: 114), te »posljednji dio Novoga zavjeta, to jest pismo Sv. Petra, epistole sv. Jakova, epistole Hebrejima i očitovanje sv. Ivana« (BUČAR 1910: 115). U pomoć im dolazi i Ivan Fabijanić, župnik u Pazinu (BUČAR 1910: 117). Znajući da je Juričić dobar prevoditelj, Klombner je u svojim nastojanjima da pronađe ljude za hrvatsku tiskaru (BUČAR 1910: 84) računao da će on prevesti čitavu Bibliju na hrvatski jezik. Međutim, Juričić je preveo pet knjiga Mojsijevih iz Staroga zavjeta, te nekoliko odlomaka za glagoljski i ćirilični drugi dio Novoga zavjeta (BUČAR 1910: 121). Što je Matija Pomazanić preveo, to Franjo Bučar (BUČAR 1910) u svojoj knjizi ne navodi. Prevoditelji su pri ruci imali i poneki stariji rukopis iz crkvenoslavenskoga razdoblja (BUČAR 1910: 216). Fran Vidic smatrao je da su se hrvatski glagoljski protestantski prijevodi evanđelja naslanjali na stare hrvatske crkvenoslavenske prijevode (POLOVIČ 1908: 56). Franjo Bučar konstatira da je »hrvatskim prevodiocima bila poznata starija crkvena hrvatska glagolska književnost, koja je medjutim takodjer, što se tiče jezika i izdanja, bila dosta nedotjerana.«(BUČAR 1910: 2014). Ivan 
Polovič utvrđuje da su prilikom priređivanja teksta Novog zavjeta prevoditelji imali pred sobom: crkvenoslavenski misal hrvatske recenzije, Lekcionar Bernardina Splićanina (LBS), Trubarjev slovenski prevod iz let 1557. i Vulgatu (POLOVIČ 1908: 94). Pritom ne navodi koji bi to crkvenoslavenski misal hrvatske recenzije bio. S druge strane, Konzul i Dalmatin u svojem opravdanju Joštu Gallenbergu i kranjskim staležima naglašavaju da namjerno nisu željeli u svojim izdanjima pisati jezikom kakvim su pisani brevijari i misali, jer »hrvatski popovi ni polovinu jezika u tim knjigama ne razumiju « (FANCEV 1916.a: 153). Kad je riječ o misalu koji je mogao poslužiti kao izvor za prevođenje, Ivan Polovič navodi Misal Pavla Modrušanina iz 1528. godine (POLOVIČ 1908: 64). Za pretpostaviti je da su prevoditelji dobro poznavali hrvatske crkvenoslavenske kodekse nastale i upotrebljavane u središnjoj Istri (budući da su i sami bili Istrani), baš kao što su to i Beramski brevijari. Nažalost, nije nam poznato kojim su se hrvatskim crkvenoslavenskim kodeksima doista i služili jer o tome nema svjedočanstava.

Brevijar je crkvena knjiga koja sadrži životopise svetaca, homilije, molitve, himne, psalme i ostale pobožne pjesme te odlomke iz Starog i Novog zavjeta. Drugi beramski brevijar $\left(\right.$ Ber $_{2}$ ) je hrvatskoglagoljski spomenik iz 15. st. Čuva se u Narodnoj in univerzitetnoj knjižnici u Ljubljani zbog čega se često naziva i Drugi ljubljanski brevijar. Čuva se pod signaturom MS 163. $\mathrm{Ber}_{2}$ je knjiga koja se upotrebljavala u Bermu no nije pouzdano je li tamo i nastala. Na temelju provedenih analiza Milan Mihaljević donosi pretpostavku da ga je pisao domaći čovjek iz središnje Istre ali da ga je prepisivao iz starijeg predloška možda pristiglog iz južnijeg čakavskog područja (MIHALJEVIĆ 2011: 138). Iako je dobro poznato i već potvrđeno ${ }^{1}$ da su protestanti napravili odlučan iskorak prema narodnom jeziku (u našem slučaju - čakavskome), zanimat će nas - na temelju konkretne usporedne analize - u kolikoj je mjeri to doista i provedeno, odnosno koliko se u njima ipak odražava poznavanje hrvatskih crkvenoslavenskih prijevoda. Dakle, namjera protestanata bila je da osvježe jezik. To osvježenje značilo je davanje prednosti osobinama čakavskog književnog jezika pred osobinama hrvatskog crkvenoslavenskog jezika.

Ovim se radom želi odgovoriti na dva pitanja. Prvo je: kolika je bliskost protestantskih prijevoda s latiničkim lekcionarima? Drugo je pitanje: kolika je mogućnost da je tekst korišten, (a možda) i nastao na prostoru srednje Istre, kao što je to $\mathrm{Ber}_{2}$, mogao biti uzorom za nastanak Novog testamenta, odnosno, koliko u Novom testamentu ima hrvatskih crkvenoslavenskih elemenata?

1 V. BUČAR 1910; DAMJANOVIĆ 2010; FANCEV 1916.a i FANCEV 1916.b; KATIČIĆ 2013; KUŠTOVIĆ; ŽAGAR 2019; ŽAGAR 2018 i dr. 
Vezano za prvo pitanje, već je rečeno da je ustanovljena bliskost protestantskih prijevoda s latiničkim lekcionarima, pri čemu se utvrdila sličnost sa Zborovčićevim lekcionarom iz 1543. godine, otisnutim u Veneciji, a riječ je o drugom izdanju LBS iz 1495. godine (POLOVIČ 1908: 94). Tomo Maretić u svom kritičkom izdanju koje je priredio 1885. godine donosi usporedbu Lekcionara Bernardina Splićanina (LBS) iz 1495. godine sa Zborovčićevim lekcionarom iz 1543. godine, te izdanjem iz 1568. godine. Razlike između Lekcionara Bernardina Splićanina iz 1495. godine $\mathrm{u}$ odnosu na Zborovčićev lekcionar iz 1543. godine su minimalne, dok su jako velike u odnosu na izdanje iz 1568. godine, ali ovaj drugi kodeks nas u ovoj analizi neće zanimati jer nikako nije mogao biti predložak za Novi testament iz 1563. godine. I sam Tomo Maretić tvrdi da je Zborovčićev lekcionar samo ponovno otisnut Lekcionar Bernardina Splićanina (LBS), s vrlo rijetkim razlikama: »A da je drugo izdanje samo preštampano prvo, to se još jače potvrdjuje, ako isporedimo oba izdanja. (...) Ja sam isporedjivao takodjer oba izdanja (...), ali ne mogu reći, da u jeziku nema baš nikake razlike medju njima; ako i jesu take razlike rijetke ali opet se mogu potvrditi.«(LEKCIONARIJ BERNARDINA SPLJEĆANINA 1885: VIII). Napomenimo da su kasnija istraživanja Vuka Tadije Barbarića pokazala da ipak nije samo riječ o prijepisu (BARBARIĆ 2017). U tekstu će se analizom pokušati utvrditi jesu li protestantski prijevodi bliski s tada moguće dostupnim latiničkim lekcionarima.

U pogledu drugog postavljenog pitanja: analiza u ovom tekstu napravljena je uspoređivanjem Prve Epistole svetoga Pavla Korinćanima (1 Kor 11,20-33) u Ber 2 kao predstavniku srednjoistarskih kodeksa (148c-149a), u LBS (90-91), tj. u Zborovčićevom lekcionaru (84-85) ${ }^{2}$ i Novom testamentu i to u njegovom drugom dijelu (GNT 37b-38a). Tom cee se usporedbom nastojati utvrditi koliki je udio crkvenoslavenskih i čakavskih elemenata u protestantskom glagoljskom Novom testamentu. ${ }^{3}$ Do sada napisana literatura o jeziku protestantskih knjiga pokazala je ono što je možda najjednostavnije

2 U proučavanom dijelu teksta (1 Kor 11,20-33) ne postoji razlika između Lekcionara Bernardina Splićanina i Zborovčićeva lekcionara. Zborovčićev lekcionar se navodi da bi se osvijestila činjenica da se Zborovčićev lekcionar ipak razlikuje od Lekcionara Bernardina Splićanina te da nije samo njegov prijepis, bez obzira što su razlike između ta dva teksta male i što $\mathrm{u}$ ovom proučavanom dijelu teksta razlika nema. U ovom radu se pod pojmom »lekcionari« podrazumijevaju i LBS i Zborovčićev lekcionar.

3 Dodajmo da je proučavanje hrvatskih protestantskih izdanja tema projekta Jezik izdanja hrvatske protestantske tiskare u kontekstu književnojezičnih smjernica XVI. st. koji vodi Mateo Žagar a financira ga Hrvatska zaklada za znanost. Uz njega na projektu sudjeluju još i Vera Blažević Krezić, Blanka Ceković, Stjepan Damjanović, Ivana Eterović i Tanja Kuštović. 
sažeo Radoslav Katičić: »Taj je jezik sasvim narodan, kako se kod protestanata mora i očekivati. Ipak su u njemu prisutni i crkvenoslavenski elementi. Nije ih mnogo, ali nisu niti samo simbolični. Odatle se razabire koliko je tradicija hrvatske pismenosti bila srođena sa svojim iskonskim liturgijskim jezikom i s jezikom crkvenoga učiteljstva.« (KATIČIĆ 2013: 92).

Još je potrebno odgovoriti na pitanje zašto je za analizu odabrana upravo Prva Epistola svetoga Pavla Korinćanima. Kad piše o Matiji Živčiću, hrvatskom protestantskom prevoditelju i propovjedniku, Franjo Bučar navodi da je on, zajedno s Ivanom Fabijanićem preveo i pregledao »epistole sv. Pavla na Rimlane, Korinćane i Galatejce« (BUČAR 1910: 2050206) te iz toga mogu pretpostaviti da njima dvojici »pripada prijevod teksta Pavlove poslanice Korinćanima (KUŠTOVIĆ 2019) koji će biti analiziran. U odabranom ulomku riječ je o dijelu teksta koji je uključen u kanonski dio mise, tj. sadrži euharistijsku molitvu koja se izgovara za vrijeme euharistijske službe: »...Ovo je tijelo moje koje je za vas...«(BIBLIJA 1983: 108201083) dakle prilikom pretvorbe, što je s liturgijskog stajališta najvažniji čin mise. ${ }^{4}$ Dakle, upravo to je tekst koji bi trebao biti jezično najstabilniji, odnosno tekst koji bi morao biti adekvatno preveden, dovoljno i precizan i uzvišen da ni na koji način ne umanji vrijednost važnog čina koji se njime iskazuje. I možda je malo vjerojatno da bi se u ovim iskazima prevoditelji usudili odmaknuti od već ustaljene hrvatske crkvenoslavenske norme koju su poznavali.

\section{MORFOLOŠKA I LEKSIČKA ANALIZA}

Ovdje je potrebno napomenuti da o tekstovima s fonološke strane neće biti riječi jer je Novi testament detaljno obradio Franjo Fancev (FANCEV 1916. a). ${ }^{5}$ On je pokazao i dokazao kako je s fonološke strane jezik glagoljskog Novog testamenta u skladu s osobinama hrvatskog jezika 16. stoljeća. LBS Franjo Fancev ne obrađuje detaljno već samo ponegdje upućuje na njegov utjecaj na Novi testament. Fonološke karakteristike jezika u Ber ${ }_{2}$ obrađuje Znanstveni centar izvrsnosti za hrvatsko glagoljaštvo i rezultati tih analiza bit će uskoro

${ }_{4}$ Ovdje treba dodati da to nije jedino mjesto u Novom testamentu na kojem se te riječi izgovaraju. Nalazimo te riječi i kod evanđelista Mateja, Marka i Luke: Matej 26,26: OVO ĴEST TILO MOĴE (40a); Marko 14,22: OVO JEST TILO MOJE (69b); Luka 22,19: OVO JEST TÊLO MOE (117a)

5 Uz to, grafemska i fonološka analiza Novog testamenta koja uključuje tekstove Novog testamenta u trima Postilama (glagoljskoj, ćirilskoj i latiničkoj) bit će objavljena u tekstu: Biblijski tekstovi uraških protestantskih izdanja u suodnosu (BLAŽEVIĆ KREZIĆ; KUŠTOVIĆ; ŽAGAR 2019). 
predočeni, a dio rezultata je već predstavljen (VRANIĆ 2018). Samo ću spomenuti da se u ovom dijelu teksta među uspoređivanim tekstovima razlikuju refleksi B pri čemu Ber ${ }_{2}$ čuva $\mathrm{B}$ (têlo, prêdahb), u Novom testamentu u ovom dijelu teksta on se bilježi ali samo kao grafijski ostvaraj ili se reflektira kao $e$ (telo, predal') ili $i$ (svit'), a u lekcionarima kao $i$ (tilo, pridal, svit). Đerv se u ovom ulomku upotrebljava za označavanje glasa $j$ (jisti, mojoi).

Kad govorimo o morfološkoj analizi, treba reći da je na ovom prilično malom uzorku nemoguće dati prikaz svih nastavaka za pojedine morfološke kategorije tako da ću se usredotočiti na ono po čemu se kodeksi međusobno razlikuju. ${ }^{6}$

\subsection{Imenice}

Analizirajući imenice utvrdila sam da su imenski nastavci u svim tekstovima usklađeni. Iznimka je imenica crkva koja u akuzativu jednine ima nastavke glavne ženske deklinacije i u GNT glasi crikvu. Ista imenica u LBS glasi crikaf, odnosno crêkavb $\left(\mathrm{Ber}_{2}\right) / 28 /$, tj. ima nastavak $v$-deklinacije. Iz toga proizlazi da je točna početna tvrdnja da je jezik GNT, kad je riječ o imenicama, usklađen s jezikom LBS (osim navedene iznimke). Na temelju jednog primjera kod imenica ne možemo tvrditi da su deklinacijski tipovi u GNT bitno različiti od deklinacijskih tipova u hrvatskom crkvenoslavenskom Ber $_{2}$.

\subsection{Zamjenice}

Analiza zamjenica pokazuje da se u Ber ${ }_{2}$, očekivano, koriste hrvatski crkvenoslavenski oblici dok na istim mjestima GNT i LBS imaju hrvatske oblike - u pravilu čakavske. Ovdje navodim i primjere koje bismo s pravom ubrojili u leksičke razlike. Međutim, namjera mi je pokazati da postoji, kad je riječ o zamjenicama, velika morfološka razlika između GNT i LBS s jedne strane i Ber ${ }_{2} \mathrm{~s}$ druge strane. Naravno, nije ništa neobično da na crkvenoslavenskoj osnovi nalazimo crkvenoslavenski nastavak kao što nije neobično ni što na hrvatskoj osnovi nalazimo hrvatski nastavak. Kod primjera u kojima se koristi osnova zajednička i hrvatskom i crkvenoslavenskom jeziku u GNT i LBS uvijek nalazimo hrvatski, a u Ber ${ }_{2}$ hrvatski crkvenoslavenski nastavak.

$\overline{6}$ Kraticama u tekstu navodi se u kojem tekstu nalazimo primjer a brojka između kosih crta upućuje na »natuknicu« koja se nalazi u dodatku teksta. Iz »natuknice« u dodatku vidljiv je čitav kontekst u kojem se primjer javlja. 
- lokativ jednine ženskoga roda: $v$ krvi mojoi (GNT, LBS) : u krvi moei $\left(\mathrm{Ber}_{2}\right) / 80 /$ nastavak je u Ber ${ }_{2}$ hrvatski crkvenoslavenski

- u sintagmi: hoću vas ' hvaliti (GNT, LBS) /38/, za vas (GNT, LBS) /65/ isti akuzativ vas' imaju i GNT i lekcionari dok brevijar ima hrvatski crkvenoslavenski oblik vi $\left(\right.$ Ber $\left._{2}\right)$

- pokazna zamjenica ovaj u Novom testamentu i lekcionarima izražena je osnovom koja je zajednička i hrvatskom i hrvatskom crkvenoslavenskom jeziku (ov-), dok se u brevijaru koristi hrvatska crkvenoslavenska osnova $s$-. Vidljivo je to u svim rodovima i padežima koji se u proučavanom tekstu mogu naći:

- u nominativu muškoga roda: ovi kruh' (GNT, LBS) : hlêbb si $\left(\mathrm{Ber}_{2}\right)$ 188/

- u nominativu srednjega roda: ovo jest telo moe (GNT, LBS) : se jest $\left(\operatorname{Ber}_{2}\right) / 61 /$

- u nominativu ženskog roda: ova čaša (GNT, LBS) : siê čaša $\left(\right.$ Ber $\left._{2}\right)$ /73/

- u genitivu muškoga roda: od kruha ovoga (GNT, LBS) : ot hlêba sego $\left(\right.$ Ber $\left._{2}\right) / 107 /$

- u genitivu ženskoga roda: iz čaše ove (GNT) : ot čaše see $\left(\mathrm{Ber}_{2}\right)$ /111/

- u akuzativu srednjega roda: ovo činite (GNT) /68/ : sie tvorite /Ber $/$

- u lokativu srednjega roda: va ovom' (GNT, LBS) : va semb $\left(\right.$ Ber $\left._{2}\right)$ 139/

- u instrumentalu muškoga roda: $z$ ovim' svitom (GNT, LBS) : s' mirom'simb $\left(\mathrm{Ber}_{2}\right) / 143 /$

- Osim razlika, možemo pronaći zamjeničke oblike koji su zajednički svim tekstovima, bez obzira na fonološke razlike: ini, moe, on, $t i$ (dativ), vam.

- Povratno-posvojna zamjenica sebê u GNT i lekcionarima uvijek je iskazana nekim od refleksa »jata « dok u Ber $_{2}$ na tom mjestu neizostavno imamo $\boldsymbol{A}$, bar u proučavanom dijelu teksta:

- lokativ: sêbi (GNT), sebi (LBS) : sebê $\left(\mathrm{Ber}_{2}\right)$ /117/

- Neodređenu zamjenicu vsaki /11/ nalazimo u GNT i Ber 2 , dok je u lekcionarima zabilježen štokavski oblik svaki. Mogli bismo to uzeti kao dokaz pretpostavci da se u GNT nije nužno štokavizirao svaki oblik koji je mogao biti štokaviziran. 
- I Ber ${ }_{2}$ i GNT koriste zamjenicu čto /35/ dok na istom mjestu lekcionar ima oblik ča. Pritom je ovaj čto u Ber ${ }_{2}$ hrvatski crkvenoslavenski oblik. Analizirajući zamjenicu čto u Novom testamentu, Mateo Žagar dolazi do zaključka da bismo to čto trebali čitati što, ${ }^{7}$ premda je bilježen crkvenoslavenskom grafijom, kao uostalom i neki drugi leksemi (npr. glagol jêite).

\subsection{Pridjevi}

Kod pridjeva, što se sklonidbe tiče, na odabranom dijelu teksta nema većih razlika. Razlika je u primjeru u akuzativu: crikvu bož’ju (GNT) / cr(ê)kavb B(o)žiju $\left(\mathrm{Ber}_{2}\right) / 29 /$ i tu možemo govoriti samo o fonološkoj razlici, odnosno razlika je u tome je li došlo do fakultativnog duljenja poluglasa ispred glasa $j$ u 㖀, a jest kod Drugog beramskog brevijara, pa ovdje umjesto 炤 imamo hrvatski refleks $i$, dok se u GNT-u zadržalo samo grafijsko bilježenje poluglasa (usp. LUKEŽIĆ 2012: 142).

- U primjeru vêčera $G($ ospo)dnja (GNT, LBS) : $g$ (ospo)d'skie večere $\left(\right.$ Ber $\left._{2}\right) / 6 /$ riječ je o različitim tvorbenim nastavcima (-n- : $-s k$-), pri čemu GNT i LBS imaju riječ sakralnog značenja (SKOK 1971: 594) dok $\mathrm{Ber}_{2}$ na istom mjestu ima značenje koje je nešto šire, ali uključuje i spomenuto sakralno značenje. U Hrvatskom crkvenoslavenskom književnom jeziku nalazimo objašnjenje za sufiks -an da je taj »sufiks u posvojnom značenju posve ograničen: susreće se u zatvorenoj skupini osnova koje znače srodstvo (...) i još nekoliko pojedinačnih izvedenica, npr. vladičań, gospodań« (HCJ 2014: 153). U primjeru gospod'skie nastavak na imensku osnovu je -ski koji pokriva šire značenje od sakralnog. ${ }^{8}$ To ne znači da $\mathrm{Ber}_{2}$ ne koristi spomenuti pridjev gospodni, on se u sintagmi čaša gospodnja javlja na svim mjestima u ovom tekstu, ali u različitim padežnim oblicima: da bude pil' iz' čaše $g($ ospo)dnê (GNT) : bude piti čaše $g(o s p o) d n e ̂(L B S)$ : pьetь čašu g(ospod)nju (Ber $\left.{ }_{2}\right) / 97 /$. Iz primjera je vidljivo da u GNT-u imamo prijedložni genitiv, u LBS-u besprijedložni genitiv, a u Ber ${ }_{2}$ akuzativ. Na ovom primjeru možemo zaključiti da je pisar beramskog teksta poštovao postojeće norme o pridavanju pridjeva imenici (čaša gospodnê), ali i otišao korak dalje u primjeru gospod'skie večere gdje uz vjerojatno ustaljeni poznati pridjev

7 »...iako grafički predstavlja staroslavensku tradiciju, pretpostavljamo izgovor ‘što': nasuprot čakavskome 'ča' «(ŽAGAR 2018: 28).

8 Ovaj primjer bi prije svoje mjesto našao u tvorbi riječi, ali budući da se o tvorbi riječi u radu ne govori, stavljen je na ovo mjesto. 
gospodnê dodaje imenici večere ipak pridjev gospod'skie. S druge strane, prevoditelj Novog testamenta, ne želeći se možda u ovom, ipak kanoniziranom tekstu, izlagati opasnosti da ga se proziva zbog ubacivanja »svjetovnih« oblika, odlučuje se za oblik gospodnê u oba slučaja (čaša gospodnê i vêčera gospodnja).

\subsection{Glagoli}

Dosadašnja istraživanja liturgijskih tekstova iz 15. stoljeća (pa tako i Ber ${ }_{2}$ ) pokazala su da glagolski sustav, morfološki gledano odgovara stanju u kanonskim starocrkvenoslavenskim spomenicima. Ujedno, to je dio jezika koji se najmanje promijenio (HCJ 2014: 205). Elemente hrvatskog crkvenoslavenskog jezika nalazimo u protestantskom glagoljskom Novom testamentu, kao što ih nalazimo i u LBS, ali ti su elementi raspoređeni samo na određena vremena i određena lica.

Prezentski nastavak u Novom testamentu koji odgovara hrvatskom crkvenoslavenskom nastavku nalazimo u 1 . licu jednine $(-u) .{ }^{9}$ Međutim, treba reći da je ovaj nastavak osobina i svih razdoblja čakavskog hrvatskog književnog jezika (KUZMIĆ; KUZMIĆ 2015: 45) te štokavskog hrvatskog književnog jezika (KUZMIĆ; KUZMIĆ 2015: 86-87) pa ne možemo govoriti o preuzimanju hrvatskog crkvenoslavenskog nastavka, već o nastavku koji je zajednički i hrvatskom crkvenoslavenskom, čakavskom i štokavskom književnom jeziku. Taj nastavak očekivano nalazimo i u lekcionarima i u Ber ${ }_{2}$.

- Nastavak - $u$ za 1. lice jd. prezenta nije jedini nastavak u glagoljskom Novom testamentu. Uz njega nalazimo i hrvatski nastavak $-m$ u primjerima: hvalim' (GNT) za razliku od hvalju (LBS) i pohvalju $\left(\right.$ Ber $\left._{2}\right) / 41 /$.

- U 3. licu jednine i Novi testament i lekcionar imaju hrvatske nastavke a Ber ${ }_{2}$ hrvatske crkvenoslavenske: predae (GNT), pridaje (LBS) : predast' $\left(\mathrm{Ber}_{2}\right) / 66 /$; pride (GNT, LBS) : pridetъ $\left(\mathrm{Ber}_{2}\right) / 91 /$; bude (GNT, LBS) : budetb $\left(\mathrm{Ber}_{2}\right)$ /100/; iskusi (GNT, LBS) : iskušaet $\left(\mathrm{Ber}_{2}\right) / 102 /$. Kod zadnjeg primjera možemo utvrditi da je iskusi oblik glagola iskusi$t i$, a iskušaet glagola iskušati.

- U 1. i 3. licu množine također su hrvatski nastavci u Novom testamentu i lekcionarima, a hrvatski crkvenoslavenski u brevijaru: budemo osueni (GNT), izginemo (LBS) : osudim'se $\left(\mathrm{Ber}_{2}\right) / 146 /$; spê mnozi (GNT, LBS) : s'petb mnozi $\left(\mathrm{Ber}_{2}\right) / 129 /$.

9 Primjer za nastavak - $u$ u ovom malom uzorku ne nalazimo, ali je posvjedočen u Novom testamentu (FANCEV 1916.b: 40). 
- Prezent svršenih glagola ima futursko značenje. Na isti način prezent je izražavao futursko značenje u Drugom beramskom brevijaru dok se u Novom testamentu, i ponekad u lekcionarima futur I. izražava pomoću glagola htjeti ili biti i infinitiva glagola (ću reći (GNT, LBS) : reku $\left(\mathrm{Ber}_{2}\right)$ /37/; budete piti (GNT), hoćete piti (LBS) : pbete $\left(\mathrm{Ber}_{2}\right)$ /84/.

- U primjeru: hoću vas' hvaliti (GNT) : hvalu vas (LBS), pohvalu vi $\left(\mathrm{Ber}_{2}\right)$ /38/ vidimo da i lekcionari i brevijar koriste prezent da bi njime izrazili buduce vrijeme za razliku od Novog testamenta koji upotrebljava futur I.

- Na istim mjestima često dolazi do razlike u upotrebi futura I. i futura II. između lekcionara i Novog testamenta: budete blagovati (LBS) : budete jili (GNT) dok na istom mjestu brevijar ima postojano prezentski oblik u funkciji futura ês'te $\left(\right.$ Ber $\left._{2}\right) / 87 /$.

- Razlike postoje i u upotrebi drugih vremena. Tako Novi testament i lekcionar imaju perfekt, a brevijar aorist (sam predal (GNT, LBS) : prêdahb $\left(\mathrm{Ber}_{2}\right)$ /47/; Novi testament i lekcionar aorist, a u brevijaru nalazimo aktivni particip preterita I.: v'ze (GNT), vaze (LBS) : priêmb $\left(\mathrm{Ber}_{2}\right) / 52 /$.

- U primjeru ako bismo se sudili (GNT, LBS) : ace bihomb osueni bili $\left(\mathrm{Ber}_{2}\right) / 132 / \mathrm{u}$ oba slučaja imamo kondicional, ali brevijar ima poseban oblik aorista glagola biti.

- Imperativ za 3. lice jednine je sintetski u Novom testamentu i lekcionaru jêi (GNT), blaguj (LBS), pii (GNT, LBS), dok je u brevijaru analitički - tvoren pomoću čestice $d a$ i prezenta glagola: da êstb $\left(\mathrm{Ber}_{2}\right) / 105 /, d a$ pbetb $\left(\right.$ Ber $\left._{2}\right) / 109 /$. Franjo Fancev kao poseban oblik imperativa glagola za 2. lice množine navodi jêite koji nalazimo u Novom testamentu (FANCEV 1916.a: 130). U lekcionarima taj oblik glasi blagujte, a u brevijaru êdite /60/.

- Participi su češće u upotrebi u brevijaru nego u Novom testamentu i lekcionaru. U brevijaru se oni dekliniraju (s'hodećim, v'zdav, glagole, sudimi) za razliku od lekcionara (kupeći se, uzdajući, razmišljajuće) i Novog testamenta u kojem su rjeđi nego u ostala dva teksta (razmišljajuć').

- Na mjestu aktivnog participa prezenta koji nalazimo u brevijaru, u Novom testamentu i lekcionarima imamo hrvatski oblik participa: govoreći (GNT, LBS) : glagole $\left(\mathrm{Ber}_{2}\right)$ /76/ ili zavisnu rečenicu: potom' kad' hvali v'zda (GNT, LBS) : hv(a)lu v'zdavb $\left(\mathrm{Ber}_{2}\right)$ /56/; kad smo sueni (GNT, LBS) : sudimi že $\left(\mathrm{Ber}_{2}\right) / 140 /$. 


\subsection{Leksik}

Leksička analiza provedena na svim vrstama riječi ukazuje nam na ono što je za Ber ${ }_{2}$ očekivano, da su leksemi hrvatski crkvenoslavenski, kad god to mogu biti. A kad ne mogu, onda su zajednički i hrvatskom i hrvatskom crkvenoslavenskom jeziku. S druge strane, leksemi upotrijebljeni u glagoljskom Novom testamentu i LBS uvijek pripadaju hrvatskom jeziku. U skladu je to s nastojanjem da tekst bude razumljiv što većem broju vjernika. Vuk Tadija Barbarić pokazuje da je Fancev istaknuo da se kod Bernardinova lekcionara (...) gledalo da se tekst prilagodi gramatički i leksički potrebama narodnoga govora (BARBARIĆ 2017: 51). Na istom su tragu i hrvatski protestanti prilikom prevođenja Novog testamenta koji su svjesni toga da je jezik kojim su liturgijske knjige pisane nejasan. Upozorava na to u svom na njemačkom jeziku pisanom predgovoru glagoljskog Novog testamenta Primož Trubar: »Hrvati, Dalmatinci, Bosanci, Srbi i Bugari također imaju vlastite jezike, pisane dvjema vrstama pisama ili slova, ali do sada nisu imali nijednu cjelovitu Bibliju ili katekizam na svome jeziku, nego su si morali pomagati brevijarima, molitvenicima i misnim knjigama, a te su knjige napisane prije mnogo godina i tako su nejasne i nerazumljive, ispremiješane u prijevodu s mnogim latinskim riječima, da čak ni sami svećenici ne razumiju mnoge riječi u nedjeljnim Evanđeljima.« (NT1: 20). Zadaća protestantskih izdanja bila je učiniti tekstove razumljivima, a to su najbolje mogli služeći se hrvatskim leksikom.

Kod imenica navedimo primjere: Isus (GNT, LBS) : is $(u) h(r b s t) b\left(\mathrm{Ber}_{2}\right)$ /49/, spomenut'je (GNT, LBS) : vbspominanie $\left(\mathrm{Ber}_{2}\right.$ )/84/, svitom (GNT, LBS) : mirom' $\left(\mathrm{Ber}_{2}\right)$ /145/. Zanimljivo je da i GNT i LBS upotrebljavaju leksem kruh za razliku od Ber $_{2}$ u kojem je upotrijebljen leksem hlêbb /53, 95/. Razlika postoji i upotrebi leksema gospodin (GNT, LBS) i gospodb $\left(\right.$ Ber $\left._{2}\right)$. Skok za riječ gospod navodi da pripada sakralnom rječniku u značenju bog (SKOK 1971: 594). U izvancrkvenom značenju gospod je dobio sufiks -in već u starocrkvenoslavenskom jeziku (SKOK 1971: 594). U izboru između gospod i gospodin protestanti se odlučuju za izvan crkveni leksem i značenje gospodin premda riječ upotrebljavaju u crkvenom kontekstu. Bez obzira na to, nisu iskočili iz uobičajene uporabe jer, rekli smo, leksem gospodin je s vremenom dobio i crkveno značenje.

Zamjenice su već spomenute u morfološkoj analizi te vrste riječi. Hrvatske crkvenoslavenske lekseme ne nalazimo u GNT-u (iznimka bi mogla biti zamjenica čto u toj grafijskoj pojavnosti), za razliku od Ber $_{2}$ u kojem nalazimo hrvatske crkvenoslavenske oblike i oblike koji su zajednički i hrvatskom 
crkvenoslavenskom i hrvatskom jeziku. $k i$ : iže /112/, ko : eže /64/, ovo : sie /68/, ova : siê /77/, ovoga : sego /107/, ovim': simb /145/, vas:vi /38/, ja: az' 152/. Naravno, ima leksema koji su zajednički svim trima tekstovima kao što su: $t i$, vi, svoju, ini, onih, moe.

Kod glagolskih leksema postoje male razlike. Nalazimo ove parove: pogr'juete (GNT, LBS): obêdite $\left(\right.$ Ber $_{2}$ ) /20/. Zanimljiv je leksem za značenje jesti koji u glagoljskom Novom testamentu glasi, kao što je već u imperativu spomenuto jeite, u Ber ${ }_{2}$ nalazimo istu osnovu s oblikom êdite, dok LBS uvijek ima drugačiji leksem blagujte /60, 87, 105, 113, 118/. Mogli bismo možda reći da se na ovom primjeru vidi da su protestantski prevoditelji ponekad nastojali približiti staroslavensku tradiciju budućim čitateljima.

Što se tiče nepromjenjivih riječi, priređivači Novog testamenta upotrebljavaju hrvatske lekseme, a tako je u većini primjera i u lekcionarima, premda i u lekcionarima nalazimo hrvatskih crkvenoslavenskih primjera: tako (GNT) : jure (LBS, Ber ${ }_{2}$ ) /4/; ili (GNT, Ber ${ }_{2}$ ) : jeda li (LBS) /23/. Opet, očekivano, u Ber ${ }_{2}$ nalazimo tradicionalne, hrvatske crkvenoslavenske lekseme (êko, tembžde, aĉe, ot, doiděže, eliko, ubo) a u Novom testamentu i lekcionarima hrvatske lekseme (da, zato, ako, od, dokle, koliko, stanovito). Česticu že ima samo brevijar. Prijedlog $v / v a$ nalazimo u Novom testamentu, u brevijaru nalazimo $v$, lekcionari imaju štokavsko $u$ /39, 79/. Prijedlog $z$ koji nalazimo u Novom testamentu, u lekcionaru i u Ber ${ }_{2}$ zabilježen je kao $s$ : $z$ ovim'svitom, odnosno s ovim svitom u lekcionarima is s'mirom'simb u Ber 2 /145/. Naravno, i kod nepromjenjivih riječi ima onih koje su zajedničke svim trima tekstovima: tada, tako, i, iz, na, $k$.

\section{ZAKLJUČAK}

Vezano za prvo pitanje na koje se želi odgovoriti ovim istraživanjem, a koje se odnosi na razinu bliskosti protestantskih prijevoda s latiničkim lekcionarima: možemo se složiti s pretpostavkom da su latinički lekcionari bili podloga za oblikovanje bar u dijelu teksta 1 Kor 11,20-33 i to na temelju činjenice da su hrvatski oblici često podudarni, premda ne uvijek, s onima koje nalazimo u LBS, odnosno Zborovčićevu lekcionaru za kojeg možemo pretpostaviti da je protestantima, s obzirom na godinu kada je otisnut (1543) bio dostupniji. U tom smislu, možemo reći da su se prevoditelji Novog testamenta poslužili lekcionarom kao uzorom ali da su neka mjesta preveli neovisno o njemu.

U pogledu drugog postavljenog pitanja, a koje se odnosi na vjerojatnost da je neki tekst korišten, (a možda) i nastao na prostoru srednje Istre (poput 
Ber $_{2}$ ), mogao biti uzorom za nastanak Novog testamenta te koliko u Novom testamentu ima hrvatskih crkvenoslavenskih elemenata: iz analize je vidljivo da hrvatskih crkvenoslavenskih elemenata nema ni na morfološkom ni na leksičkom planu, bar što se tiče ranije spomenutog dijela novozavjetnog teksta. Treba spomenuti i to da kod imenica, gotovo da nema niti u Ber ${ }_{2}$ nastavaka koji bi bili isključivo hrvatski crkvenoslavenski (iznimka je spomenuti akuzativ imenice crêkva: crêkavb), kao što ih nema ni u LBS. Kategorija pridjeva $\mathrm{u}$ proučavanom dijelu teksta ne pokazuje nikakve razlike $\mathrm{u}$ analiziranim tekstovima. Tu možemo govoriti samo o fonološkim i tvorbenim razlikama. Za razliku od imenica i pridjeva, kod zamjenica postoje one koje su u GNT ili isključivo hrvatske (i leksički i morfološki), ili pripadaju zajedničkom dobru i hrvatskog i hrvatskog crkvenoslavenskog jezika pa su opet razumljive čitateljima i slušateljima teksta GNT. Kategorija glagola je, mogli bismo reći, usklađena s kategorijom zamjenica kad je riječ o odnosu hrvatskoga prema hrvatskom crkvenoslavenskom. Naime, kao i kod zamjenica, i kod glagola GNT i LBS imaju nastavke i oblike koji pripadaju hrvatskom jeziku dok Drugi beramski brevijar ima hrvatske crkvenoslavenske osobine. Hrvatski crkvenoslavenski leksik je u potpunosti zamijenjen hrvatskim u svim vrstama riječi u GNT.

Budući da je riječ o dijelu teksta koji donosi euharistijsku molitvu ne bi bilo neobično da su prevoditelji Novog testamenta upravo u taj dio unijeli samo male promjene, ne želeći se dovesti u eventualnu opasnost da im se zbog novog prijevoda prigovara. Međutim, važnije im je bilo to da ne iznevjere Lutherova nastojanja da jezik biblijskog teksta bude razumljiv svima onima koji ga čitaju i slušaju. 


\section{DODATAK}

Netom predstavljena analiza provedena je na tekstu: Novi testament te usporedba s Lekcionarom Bernardina Splićanina i Drugim beramskim brevijarom.

Osnovni tekst koji je transliteriran je Prva poslanica Korinćanima, 1 Kor 11,20-33, iz Novog testamenta (GNT, str. 37b-38a). Uređen je prema uobičajenim suvremenim pravilima transliteracije. Razlike koje se navode u odnosu na njega označene su kraticom LBS za latinički Lekcionarij Bernardina Spljećanina (str. 84-85) i kraticom Ber ${ }_{2}$ za glagoljski Drugi beramski brevijar (str. 148c-149a). 
KAP(ITUL). 11. 20-33

KA KORINTIOM. 11. KAP(ITUL). 37.

Kad'

vi tada kupno ${ }^{1} \mathrm{v}^{\text {' jedno mesto }}{ }^{2}$ se snidete ${ }^{3}$ : tako se

ondi ${ }^{5}$ vêčera $\mathrm{G}\left(\right.$ ospo)dnja ${ }^{6} \mathrm{ne}^{7} \mathrm{ji}^{8}$ [začto kad bi se imela

ova večera d'ržati] ${ }^{9}$ tada $^{10}$ vsaki $^{11}$ od' vas' ${ }^{12}{ }^{13} \mathrm{pr}=$

vo ${ }^{14}$ d'rži [ima ${ }^{15}$ svoju vlašću ${ }^{16}$ vêčeru ${ }^{17}{ }^{18}$ A ini zais=

to ${ }^{19}$ gladue $^{20}$, a drugi ${ }^{21}$ pijan' jest ${ }^{22}$. Ilii $^{23}$ nimate $^{24}$

hiš ${ }^{25}$ k joideniju i k pit' ju ${ }^{26}$ ? Ili ${ }^{27} \mathrm{Crikvu}^{28} \mathrm{Bož} \mathrm{ju}^{29} \mathrm{po}=$

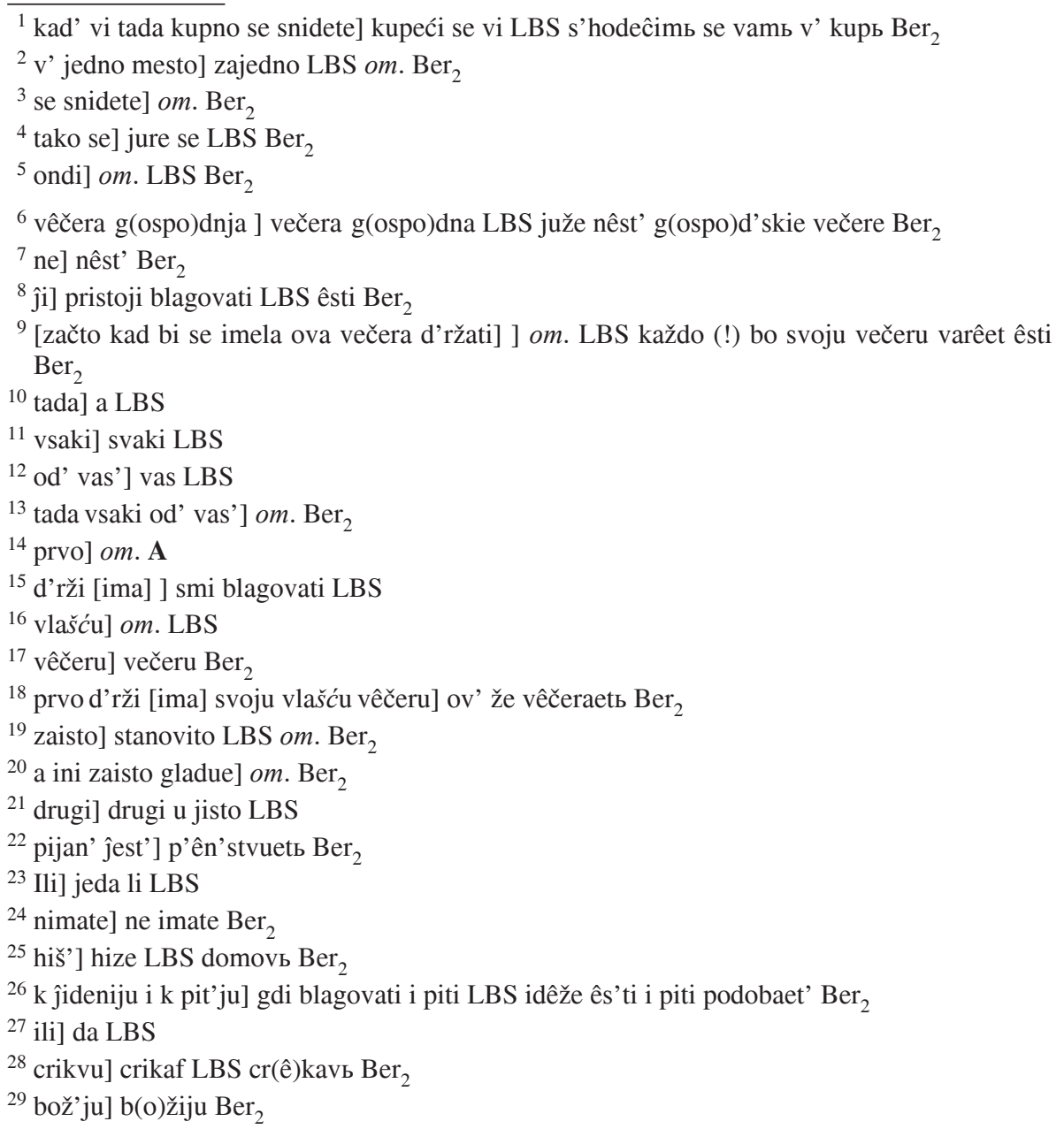




$$
\begin{aligned}
& \text { gr'juete }^{30} \text {, i stidne }{ }^{31} \text { činite }^{32} 33 \text { onih' ki nimaju }{ }^{34} \text { ? Čto }^{35} \text { ću } \\
& \text { vam' reći }{ }^{36}{ }^{37} \text { ? hoću vas' hvaliti }{ }^{38} \text { ? va ovom }{ }^{39} \text { vas } 40 \\
& \text { ne hvalim' } 41 \text {. } \\
& J^{42} \text { sam' stanovito }^{43} \text { prijelel }^{44} \text { od' G(ospo)dina }{ }^{45} \text {, to ča } \\
& \text { sam' vam' i predal' }{ }^{46}{ }^{47}: \mathrm{Da}^{48} \text { Gospodin' ISUS }{ }^{49} \text { va } \mathrm{o}= \\
& \text { noi Noći }{ }^{50} \text {, v' koi predan' bế }{ }^{51} \text {, v'ze }{ }^{52} \mathrm{Kruh}^{53} \text {, potom' }{ }^{54} \text { kad' } \\
& \text { hvali v'zda }{ }^{55}{ }^{56}, \text { razlomi }^{57} \text { i reče }{ }^{58} \text { : Vazmite }{ }^{59}, \text { jêite }^{60}
\end{aligned}
$$

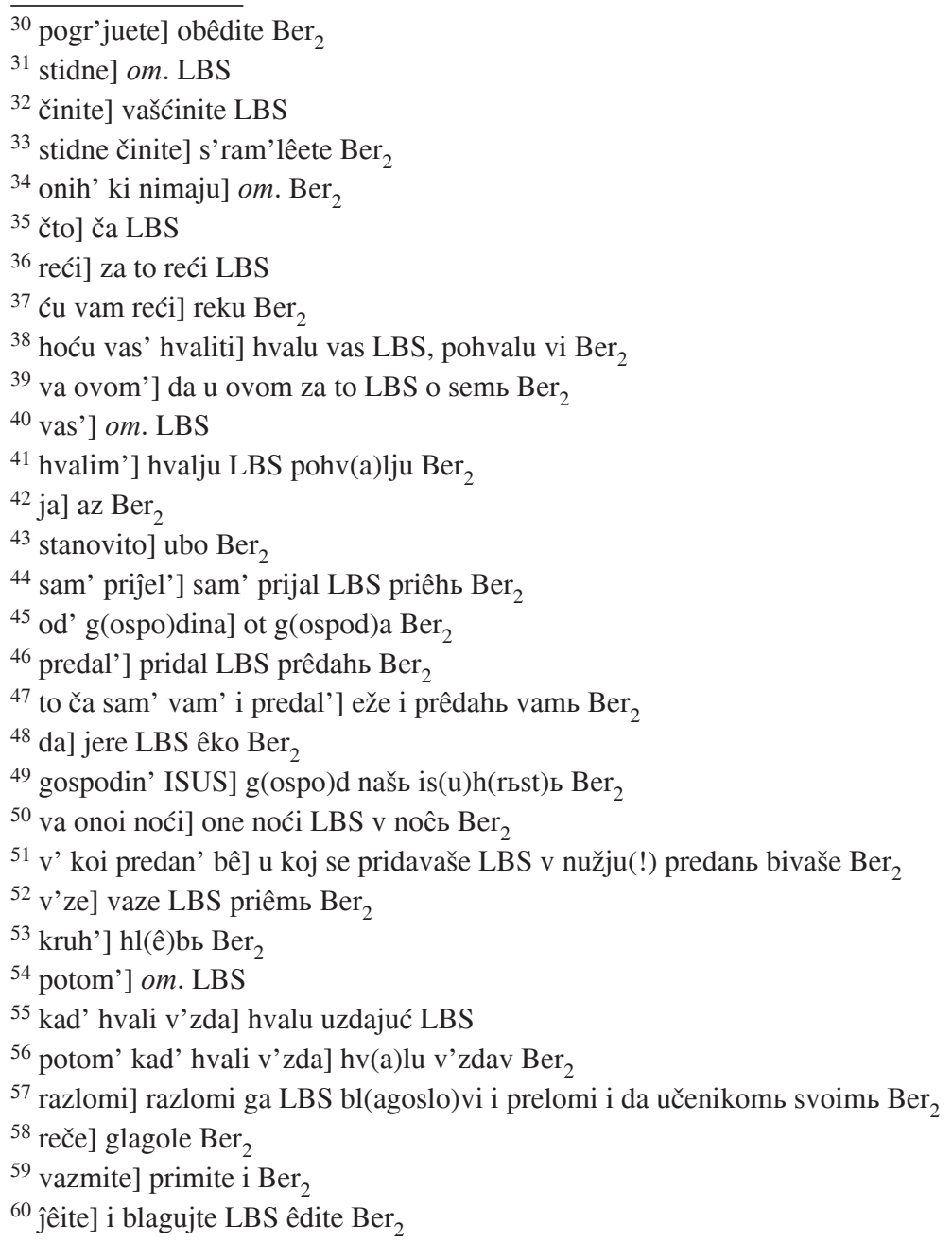


OVO $^{61}$ JEST $^{62}$ TELO $^{63}$ MOE KO $^{64}$ SE ZA VAS ${ }^{65}$

PREDAE $^{66}$, [razlama ${ }^{67}$ Ovo $^{68}$ činite $^{69}$ na vspome $=$

nut' je ${ }^{70}$ moe. Ovim' je načinom, ${ }^{71}$ i čašu ${ }^{72}$ potom, ${ }^{73} \mathrm{kad}^{\prime} \mathrm{ve}=$ čêra $^{74}{ }^{75}$ govoreći $^{76}$, OVA $^{77}$ ČAŠA JEST NOVI

ZAKON

37B [570]

KA KORINTIOM. 11. KAP(ITUL). 38.

ZAKON $^{78} \mathrm{~V}^{79}$ KRVI MOĴOI ${ }^{80}, \mathrm{Ovo}^{81}$ činite $^{82} \mathrm{ko}=$

likogodi krat ${ }^{\prime 83}$ budete piti na MOE spome=

nut' ${ }^{\prime} \mathrm{e}^{84}$ : Zač' ${ }^{85}$ kolikogodi krat ${ }^{86}$ budete $\mathrm{jili}^{87}$

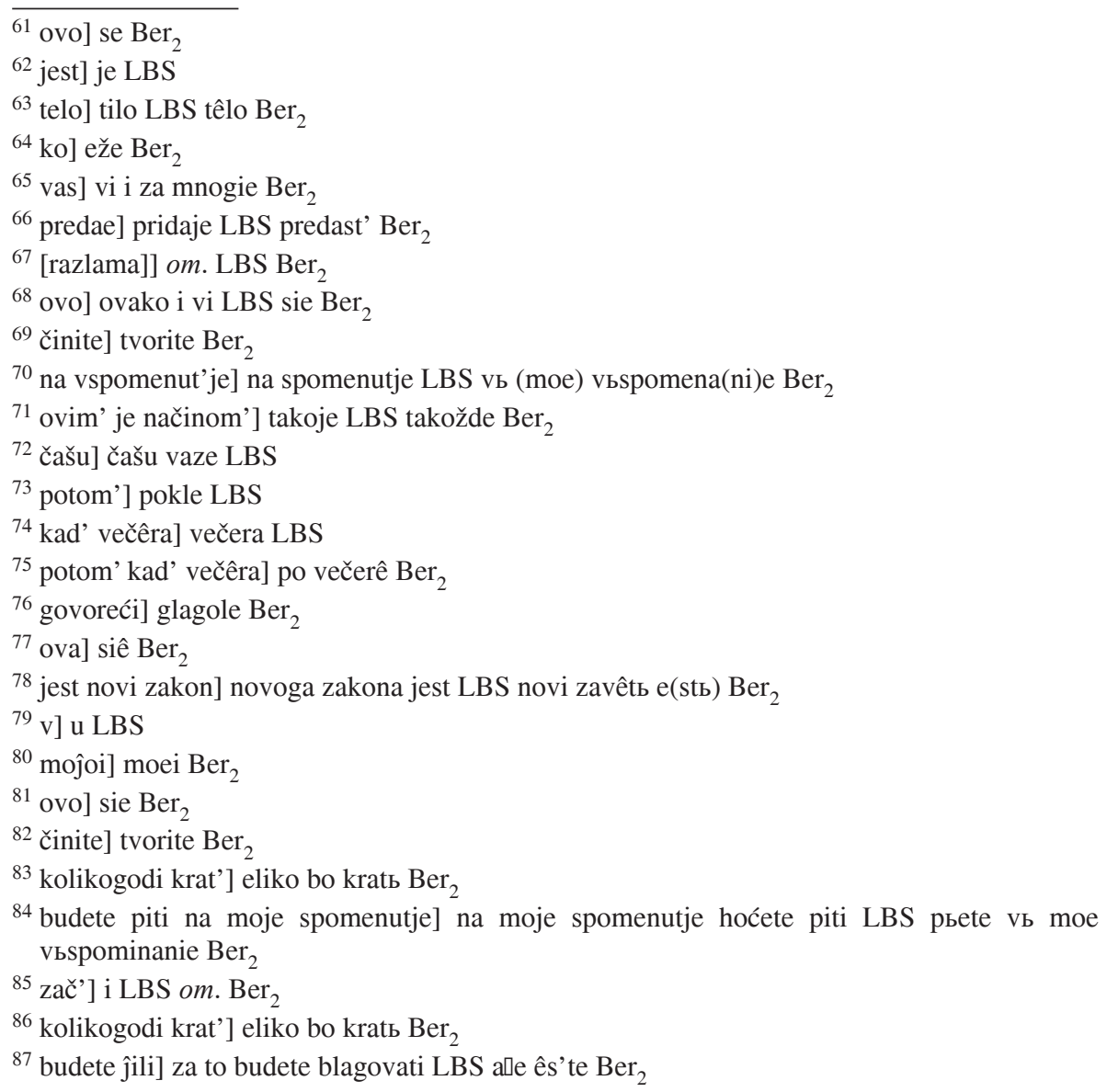


ovi Kruh' ${ }^{88}$ i iz čaše ove pili budete ${ }^{89}$, Sm'rt' $^{\text {' }}$ g(ospo)dnju navistitê ${ }^{90}$ dokle pride ${ }^{91}$.

I zato ${ }^{92}$ ki godi $^{93}$ ĵisti bude ${ }^{94}$ ovi Kruh' ${ }^{95}$, ali bude pil ${ }^{16}$ iz' čaše $\mathrm{g}\left(\right.$ ospo)dnê0 ${ }^{97}$ nedostoino ${ }^{98}$, kriv ${ }^{99} \mathrm{bu}=$ $\mathrm{de}^{100}$ têla i k'rvi G(ospo)dnêt $\hat{n}^{101}$. Iskusi ${ }^{102}$ sam' sebe ${ }^{103}$ člo=

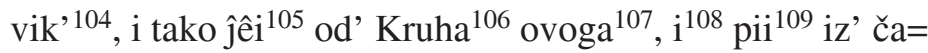
še $^{110}$ ove $^{111}$ : Jere kigodi ${ }^{112} \hat{j i}^{113}$ i pie $^{114}$ nedostoino ${ }^{115}$, on' ti osuen'je ${ }^{116}$ sêbi $^{117}$ ji $^{118}$ i pie $^{119}$ nedostoino, on' ti osuen'je sê=

\footnotetext{
88 ovi kruh'] hlêbь si Ber 2

89 iz čaše ove pili budete] i čašu budete piti LBS i čašu siju pьete Ber $_{2}$

${ }^{90}$ navistitê] ćete navišćevati LBS ispovêdaete Ber $_{2}$

91 dokle pride] doidêže pridetь $\mathrm{g}$ (ospod)ь $\mathrm{Ber}_{2}$

92 zato] tako LBS temьžde Ber $_{2}$

${ }^{93}$ ki godi] koliždo $\mathrm{Ber}_{2}$

94 jisti bude] bude blagovati LBS êstь Ber 2

95 ovi kruh'] kruha ovoga LBS hlêbı g(ospoda)nь Ber ${ }_{2}$

96 bude pil'] bude piti LBS рьеtь Ber $_{2}$

97 iz’ čaše $\mathrm{g}$ (ospo)dnê] čaše $\mathrm{g}$ (ospo)dnê LBS i čašu g(ospod)nju $\mathrm{Ber}_{2}$

98 nedostoino] nedostoên' si Ber 2

${ }^{99}$ kriv'] krivac LBS povinanь Ber $_{2}$

100 bude] budetь Ber $_{2}$

101 têla i k'rvi g(ospo)dnê] tilu i krvi gospodinji. LBS têlu i kr'vi g(ospod)ni Ber ${ }_{2}$

102 iskusi] iskusi prvo poni LBS da is'kušaet' že Ber $_{2}$

103 sebe] sebê Ber 2

104 človik'] č(lovê)kь Ber 2

105 jêi] blaguj LBS da êstı Ber 2

106 od' kruha] kruha LBS ot hlêba Ber ${ }_{2}$

107 ovoga] sego Ber $_{2}$

108 i] ili LBS

109 pii] da рьеtь Ber $_{2}$

110 iz čaše] čaše LBS ot čaše Ber $_{2}$

111 ove] om. LBS see $\mathrm{Ber}_{2}$

112 jere kigodi] iže bo aĉe $\mathrm{Ber}_{2}$

113 jii] blaguje LBS êsto Ber 2

114 ріе] рьеть $\mathrm{Ber}_{2}$

115 nedostoino] nedostoênь si grêhь i рьеtь Ber $_{2}$

116 osuen'je] om. Ber $_{2}$

117 sêbi] sebi LBS sebê Ber 2

118 jij] blaguje LBS êstь Ber $_{2}$

119 pie] рьеtь Ber $_{2}$
} 
bi ĵi i pie ${ }^{120}$, . ne razmišljajuć' ${ }^{121}$ [ne razlučujuć'] ${ }^{122}$ tê= $10^{123} \mathrm{~g}$ (ospo)dnêt ${ }^{124}$. I zato jesu ${ }^{125}{ }^{126}$ mnozi meju vami ${ }^{127}$ nemoćni i slabi ${ }^{128}$ : I spê $\hat{~}^{129}$ mnozi. Jere ${ }^{130}$ ako $^{131}$ bismo $^{132}$ se sami ${ }^{133}$ sudi= li $^{134}$ [procênili] ${ }^{135}$ stanovito ${ }^{136}$ ne bismo osueni ${ }^{137}, \mathrm{i}^{138} \mathrm{kad}=$ smo $^{139}$ sueni $^{140}$ : od' g(ospo)dina ${ }^{141}$ jesmo $^{142}$ pokarani $^{143}$, da ${ }^{144} \mathrm{z}$ ovim' svitom $^{145}$ ne budemo osueni ${ }^{146}$.

${ }^{120}$ nedostoino on' ti osuen'je sêbi ĵi i pie nedostoino] $\mathrm{om}$. LBS Ber ${ }_{2}$ (ovo je ponovljen prethodni iskaz kojeg dva puta nema niti u LBS niti u Ber $_{2}$ )

121 razmišljajuć'] razmišljajuće LBS ras'matrae Ber $_{2}$

122 [ne razlučujuć'] om. LBS Ber 2

123 têlo] tilo LBS têla i kr'vi Ber $_{2}$

${ }^{124} \mathrm{~g}$ (ospo)dnê] g(ospod)ne $\mathrm{Ber}_{2}$

125 jesu] su LBS

${ }^{126} \mathrm{i}$ zato jesu] sego radi $\mathrm{Ber}_{2}$

127 meju vami] va vas Ber $_{2}$

128 slabi] neduž'ni Ber 2

${ }^{129}$ spê] spe LBS s'petı Ber 2

130 jere] om. Ber $_{2}$

131 ako] ace $\mathrm{Ber}_{2}$

132 bismo] bihomb $\mathrm{Ber}_{2}$

133 se sami] sami sebê Ber

${ }^{134}$ sudili] om. LBS ras'suêli Ber ${ }_{2}$

135 [procênili] ] procinili LBS om. Ber

136 stanovito] om. Ber

137 bismo osueni] bismo osueni bili LBS bihomb osueni bili $\mathrm{Ber}_{2}$

138 i] a LBS om. Ber $_{2}$

139 smo] bismo LBS

140 kad smo sueni] sudimi že Ber

141 od' g(ospo)dina] ot g(ospod)a $\mathrm{Ber}_{2}$

142 jesmo] tada bismo LBS

143 jesmo pokarani] kažemb se Ber $_{2}$

144 da] da mi LBS da ne Ber 2

145 z ovim' svitom] s ovim svitom LBS s' mirom' simь $\mathrm{Ber}_{2}$

146 budemo osueni] izginemo LBS osudim' se Ber 2 


\section{IZVORI}

Ber $_{2}=$ Breviarium glagoliticum I-II = Drugi beramski (ljubljanski) brevijar, 15. st., Narodna in univerzitetna knjižnica, Ljubljana, sign. MS 163.

GNT $=$ Novi testament, 1563., Urach, Zagreb, NSK, sign. R. II. A $8^{\circ}-12 b$; DALMATIN, A.; S. KONZUL. 1563. Novi testament: 2. dio. Tübingen. (Latinički prijepis glagoljskog izvornika. 2015. Ur. D. Matak. Zagreb: Adventističko teološko visoko učilište - Filozofski fakultet Sveučilišta u Zagrebu - Školska knjiga.)

LBS = Lekcionar Bernardina Splićanina, 1495., Venecija, Franjevački samostan u Zagrebu, sign. $R$ I 4-1; izdanja: Lekcionarij Bernardina Spljećanina, po prvom izdanju od god. 1495. 1885. Zagreb: JAZU; Lekcionar Bernardina Splićanina 1495. pretisak. 1991. Split: Književni krug Split - Zavod za znanstveni i umjetnički rad Hrvatske akademije znanosti i umjetnosti Split.

\section{LITERATURA}

BARBARIĆ, V.-T. 2017. Nastajanje i jezično oblikovanje hrvatskih lekcionara. Zagreb: Institut za hrvatski jezik i jezikoslovlje.

BIBLIJA 1983 = Biblija. 1983. J. Kaštelan, B. Duda (ur.). Zagreb: Kršćanska sadašnjost.

BLAŽEVIĆ KREZIĆ, V.; T. KUŠTOVIĆ; M. ŽAGAR. 2019. Biblijski tekstovi uraških protestantskih izdanja u suodnosu. (u tisku).

BUČAR, F. 1910. Povijest hrvatske protestantske književnosti za reformacije. Zagreb: Matica hrvatska.

DAMJANOVIĆ, S. 2010. Koji je jezik za knjige prikladan (Nešto napomena uz jezikoslovne dvojbe hrvatskih protestanata). E. S.-Holzer, G. Holzer (ur.). Sprache und Leben der frühmittelalterlichen Slaven: Festschrift für Radoslav Katičić zum 80. Geburtstag. Frankfurt am Main: Peter Lang. 29037.

FANCEV, F. 1916.a. Jezik hrvatskih protestantskih pisaca 16. vijeka: Prilog historičkoj gramatici jezika hrvatskoga ili srpskoga. Rad JAZU 212: 147-225.

FANCEV, F. 1916.b. Jezik hrvatskih protestantskih pisaca 16. vijeka: Prilog historičkoj gramatici jezika hrvatskoga ili srpskoga. Rad JAZU 214: 1-112.

HCJ 2014 = GADŽIJEVA, S.; A. KOVAČEVIĆ; M. MIHALJEVIĆ; S. POŽAR; J. REINHART; M. ŠIMIĆ; J. VINCE. 2014. Hrvatski crkvenoslavenski jezik. Zagreb: Hrvatska sveučilišna naklada - Staroslavenski institut.

HRVATSKI PROTESTANTSKI PISCI. 2000. J. Bratulić (ur.). Vinkovci: Riječ.

JEMBRIH, A. 2007. Stipan Konzul $i$ »Biblijski zavod« u Urachu. Rasprave i građa o hrvatskoj knjižnoj produkciji u Urachu (1561.-1565.) i Regensburgu (1568.). Prilog povijesti hrvatskoga jezika i književnosti protestantizma. Zagreb: Teološki fakultet »Matija Vlačić Ilirik«.

KATIČIĆ, R. 2013. Hrvatski jezik. Zagreb: Školska knjiga. 
KUŠTOVIĆ, T. 2019. Jezik u Novom testamentu u odnosu na jezik u Lekcionaru Bernardina Splićanina i njegovo odnošenje prema srednjojezičnom razdoblju. Zbornik 500. godina reformacije. (u tisku).

KUŠTOVIĆ, T.; M. ŽAGAR. 2019. Jezične usporednice u Muci po Mateju u glagoljskom Novom testamentu (1562), Berlinskome misalu (1402) te u Misalu Pavla Modrušanina (1528). Pasionska baština 2018. XII. Međunarodni znanstveni simpozij »Muka kao nepresušno nadahnuće kulture». Pasionska baština Like. (u tisku).

KUZMIĆ, B.; M. KUZMIĆ. 2015. Povijesna morfologija hrvatskoga jezika. Zagreb: Hrvatska sveučilišna naklada.

LUKEŽIĆ, I. 2012. Zajednička povijest hrvatskih narječja. 1. Fonologija. Zagreb: Hrvatska sveučilišna naklada - Filozofski fakultet u Rijeci - Katedra Cakavskog sabora Grobnišćine.

LUKEŽIĆ, I. 2015. Zajednička povijest hrvatskih narječja. 2. Morfologija. Zagreb: Hrvatska sveučilišna naklada - Filozofski fakultet u Rijeci - Katedra Čakavskog sabora Grobnišćine.

MIHALJEVIĆ, M. 2011. Bilješke o jeziku Drugoga beramskoga brevijara. Tabula 9: 126-139.

POLOVIČ, I. 1908. Evangelij sv. Matevža v protestantskem glagolskem »Prvem delu Novoga testamenta« iz l. 1562. F. Ilešič (ur.). Trubarjev zbornik X. Ljubljana: Mativa slovenska, 56-73.

SKOK, P. 1971. Etimologijski rječnik hrvatskoga ili srpskoga jezika, knjiga prva, pretisak. Zagreb: JAZU.

VRANIĆ, S. 2018. Neke dijalektne značajke u Drugom beramskom (ljubljanskom) brevijaru (na primjerima prvoga dijela Temporala). I. Pavić (ur.). Sarajevski filološki susreti 4: Zbornik radova (knj. 1). Sarajevo: Bosansko filološko društvo, 245-259.

ŽAGAR, M. 2018. Elementi leksičkog odabiranja u izdanjima hrvatskih protestanata (Urach, 1561-1564): kontekst i metodološke pretpostavke. Botica, S.; M. Malnar Jurišić; D. Nikolić; J. Tomašić; I. Vidović Bolt (ur.). Hrvatski prilozi 16. međunarodnom slavističkom kongresu. Zagreb: Hrvatsko filološko društvo, 213-224.

ŽAGAR, M. 2018. Jezik izdanja uraške tiskare u svjetlu ranonovovjekovnih koncepcija književnog jezika. D. Božić Bogović (ur.). Reformacija u Europi i njezini odjeci: Zbornik radova. Osijek: Filozofski fakultet - Visoko evanđeosko teološko učilište (u tisku). 


\title{
Summary
}

\section{Tanja Kuštović}

\section{A POTENTIAL INFLUENCE OF THE ISTRIAN CHURCH SLAVONIC CODICES (NAMELY THE SECOND BERAM BREVIARY) ON THE URACH TRANSLATION OF THE GLAGOLITIC NEW TESTAMENT}

The Protestant edition of the New Testament was printed in Urach near Tübingen (the $1^{\text {st }}$ part in 1562 and the $2^{\text {nd }}$ in 1563). It is a known fact that Stipan Konzul and other Istrian priests participated in its translation. All of them were well acquainted with Church Slavonic codices, such as the Beram breviaries, that originated and were used in central Istria. Even though it has already been confirmed that the Protestants took a decisive step towards the vernacular, a detailed comparative analysis will precisely illustrate how extensive it was and to what extent the breviaries reflect the knowledge of Church Slavonic translations. Also, similarity has been established between the Protestant translations and the Latin lectionaries, namely the Zborovčić Lectionary printed in Venice in 1543, which is, in fact, the second edition of Lectionary of Bernardin from Split (1495). The analyses were conducted on the text of the First Epistle of St.Paul to the Corinthians (1 Kor 11,20-33), as part of the $15^{\text {th }}$ century Second Beram Breviary, representing the codices of Central Istria, the Lectionary of Bernardin of Split and in the second part of the printed Protestant glagolitic New Testament. The results show that the Chakavian, i.e. Croatian elements are predominant in the New Testament, while the share of Church Slavonic elements in this part of the text is insignificant.

Keywords: New Testament, lectionary, breviary, Old Church Slavonic language, Croatian language

\author{
Tanja Kuštović \\ Faculty of Humanities and Social Sciences \\ Zagreb (Croatia) \\ tanja.kustovic@ffzg.hr
}

